\title{
Drying Shrinkage and Rapid Chloride Penetration Resistance of Recycled Aggregate Concretes Using Cement Paste Dissociation Agent
}

\author{
Sungchul Yang * and Hyewon Lee
}

Citation: Yang, S.; Lee, H. Drying Shrinkage and Rapid Chloride

Penetration Resistance of Recycled Aggregate Concretes Using Cement Paste Dissociation Agent. Materials 2021, 14, 1478. https://doi.org/ $10.3390 /$ ma14061478

Academic Editor:

Malgorzata Ulewicz

Received: 8 February 2021

Accepted: 11 March 2021

Published: 17 March 2021

Publisher's Note: MDPI stays neutral with regard to jurisdictional claims in published maps and institutional affiliations.

Copyright: (C) 2021 by the authors. Licensee MDPI, Basel, Switzerland. This article is an open access article distributed under the terms and conditions of the Creative Commons Attribution (CC BY) license (https:/ / creativecommons.org/licenses/by/ $4.0 /)$.
School of Architectural Engineering, Hongik University, 2639 Sejong-ro Jochiwon, Sejong 30016, Korea; lhw9473@g.hongik.ac.kr

* Correspondence: scyang@hongik.ac.kr or scyang00@gmail.com; Tel.: +82-44-860-2561; Fax: +82-44-865-2796

\begin{abstract}
In the present study, a recycled concrete aggregate (RCA) coating treatment using a cement paste dissociation agent (CPDA) with different mixing methods was newly incorporated in RCA concrete mixtures. First, a preliminary test program was conducted to determine the proper dosage of the CPDA solution throughout its RCA concrete test results from compressive strength, flexural strength, and elastic modulus. Then, a series of experimental tests were carried out to investigate the effect of RCA coating treatment, different mixing method such as the equivalent mortar volume (EMV) method and conventional method, and different RCA replacement ratios on durability test results of RCA concrete such as drying shrinkage values and rapid chloride penetration test (RCPT) values. The test results showed that all RCA concretes mixed with the coated RCAs were found to be workable regardless of different mix methods, with the slump and air contents of all the mixes being almost identical. All the concrete specimens, which were mixed with the coated RCAs with CPDA solution, represented lower drying shrinkage and RCPT values than those mixed without RCA coating treatment, regardless of different mix proportioning methods or RCA replacement ratios. This holds for the concrete specimens proportioned with the EMV method, regardless of different RCA replacement ratios.
\end{abstract}

Keywords: recycled concrete aggregate; cement paste; dissociation agent; RCA coating; mixture proportioning

\section{Introduction}

It is widely acknowledged that various types of waste materials can be transformed into recycled aggregates, powders, or additives and are used in concrete. Ceramic materials have been used as ceramic powder and ceramic aggregates in concrete [1]. This use of glass waste in concrete production and its advantages were summarized well by Zegardło et al. [2], and recent studies related to the use of rubber aggregates and chips were reported by Guettla et al. [3]. Wood chips can also be used for wood plastic composite paver blocks [4].

Recycled concrete aggregate (RCA) is one of many types of recycling aggregates that are used for concrete. RCA is known to be more porous, less dense, and more heterogeneous than natural aggregates. However, the residual mortar (RM) adhering to RCA has a negative impact on the concrete properties. Additionally, it has been reported that RM in RCA reduces the compressive strength and elastic modulus by up to $42 \%$ and $45 \%$, respectively [5]. The data reported for Federal Highway Administration (FHWA) also revealed deceases of up to $30 \%$ and $50 \%$ in the coefficient of thermal expansion and permeability, respectively [6].

Numerous research teams have carried out experimental studies with the goal of enhancing the material properties of RCA concrete. These studies include high-quality RCA produced from precast or preserved quality concrete [7-9], the two-lift paving method [10], 
improvement of the mixing process [11,12], the use of oil-contaminated sand [13], new mixture design methods [14-17], strengthening through residual mortar (RM) coating [18-22], and supplementary cementitious materials.

First, high-quality RCA can be obtained from precast concrete [7], concrete sleepers, and returned concrete mixtures $[8,9]$. RCA acquired from such concrete can produce reliable products of consistent quality and can reduce the cost of sorting aggregates during processing.

Next, two-lift concrete paving has been successfully adopted and employed in Western Europe and the U.S. This method involves the use of low-quality RCA concrete in the lower layer of the concrete pavement. Two-lift construction using recycled concrete in the lower layer has been reported to provide the greatest impact socially and environmentally [10]. In a similar way, it was reported by Siddika et al. [23] that RCAs with other construction byproducts can be used with the application of additive manufacturing, so-called, 3D printing.

The application of oil-contaminated sand in concrete was considered effective in enhancing concrete strength properties. Abousning et al. [13] reported that the presence of crude oil up to $4 \%$ could improve the properties of mortar compared to the uncontaminated samples.

After the two-stage mixing approach (TSMA) [11] was introduced, a triple mixing procedure [12] was presented for manufacturing strong and durable RCA concrete. The triple mixing process divides the mixing process into 3 steps. The first step involves coating the mixed coarse aggregate with additives and a fixed quantity of water. The second step adds cement and fine aggregates, and the last step mixes in the remaining amount of water and plasticizer. Increased density, water absorption performance, and strength properties were reported.

Improved mixing methods for RCA concrete have also been proposed by a number of other researchers [14-17]. The equivalent mortar volume method was proposed by Fathifazl et al. [14] and received significant interest. In this method, RM was considered part of the total mortar needed for concrete. Additionally, a method that processes a portion of the RM as mortar and the remainder as aggregates was presented [15]. Gupta et al. [16] proposed the equivalent coarse aggregate mass method. The major concept behind this method is processing the mortar adhered to the RCA as sand. New approaches to improving existing mixing methods have continued to be presented and consider the properties of RM of RCA after Fathifazl et al. [14], such as the identical mortar volume design method [17]. Through these new mixing methods, it was shown that the mechanical strength and drying shrinkage of RCA concrete improved to a level similar to the properties of concrete using natural aggregates.

Researchers also investigated the strengthening of RM. Various materials were used to fill pores and interfacial transition zones (ITZs) to improve RCA quality [18-22], including polyvinyl alcohol (PVA) solution [19], siloxane and silane polymer solutions [20], and pozzolanic material slurry [21]. Overall, the surface treatment materials mentioned above helped reduce water absorption in RCA. Recently, the bio-deposition method was introduced as a way to enhance RCA quality [22]. This method used bacteria to produce calcium carbonate on the cell surfaces near the pores of ITZs (when appropriate calcium sources existed). Water absorption and compressive strength were improved using this method.

Drying shrinkage is a very important property of cementitious composites influencing their durability. Several models to predict the concrete drying shrinkage using influential factors have been empirically proposed in terms of slump, air content, fine aggregate, cement content, compressive strength, relative humidity, and volume-to-surface ratio, etc. [24,25]. In addition, it was reported that RCA treatment by PVA solution [19] affects concrete drying shrinkage. It has been widely accepted that the use of more RCA in the conventional concrete mix leads to an increase in drying shrinkage $[5,6,8,9,11,17]$. Some researchers summarized that drying shrinkage of the RCA concrete exhibited a 6-111\% increase in 11 studies [5] while a 20-50\% increase for coarse RCA and $70-100 \%$ increase for coarse and fine RCA in concrete pavement research areas [6] compared to that of the natural aggregate concrete. 
Chloride penetration resistance, which is a measure of concrete durability, is important in reinforced concrete structures as well as plain concrete structures that do not use rebars. The presence of chloride ions was found to affect the spalling of concrete pavement below the freezing temperature of the pore solution and increased the saturation state of rebar corrosion [26]. The Rapid Chloride Penetration Test (RCPT), which is another such test, provides a diffusion-related conductivity measurement and index, where a higher RCPT value indicates greater concrete diffusion [26]. Factors that affect the RCPT include the compressive strength [26]; mineral admixtures such as fly ash [27-29]; aggregates [8,30-33]; curing conditions such as autoclaving, steam curing, and normal curing [34]; pore size [26,27]; RCA replacement ratio [35-37]; specimen temperature [38-40]; regional environment conditions [26]; test conditions [40]; multiple-stage mixing approaches [41,42]; and sodium silicate and silica fume coating of the RCA aggregate [41,42]. Especially, the RCA coating was observed to fill the cracks and pores using the ITZ of the concrete sample through microstructural analysis [41,42].

The above studies highlight the importance of an idealized mixing process, a mix proportioning method, ITZ strengthening, and a coating method to provide enhanced mechanical properties for RCA concretes. However, most previous studies have been limited to investigating the mechanical strength properties of RCA concretes. Readers may notice that, so far, no research determining the effect of RCA coating treatment by cement type solutions has been conducted on durability properties such as drying shrinkage and chloride ion penetration resistance. Thus, in the present study, an RCA coating treatment using a cement paste dissociation agent (CPDA) with different mixing methods was newly incorporated in RCA concrete mixtures. First, a preliminary test program was conducted to determine the proper dosage of CPDA solution using its RCA concrete test results on compressive strength, flexural strength, and elastic modulus. Then, a series of experimental tests were carried out to investigate the effect of RCA coating treatment, different mixing methods such as the equivalent mortar volume (EMV) method and conventional method, and different RCA replacement ratios on the durability test results of RCA concrete such as drying shrinkage values and RCPT values [43]. Therefore, the results of this study provide guidance that can be used to assess the beneficial increment in durability properties by adopting RCA coating treatment with the optimized mix proportioning method.

\section{Experimental Program}

\subsection{RCA Production}

This experimental study used RCAs produced from two different sources in South Korea. The RA aggregate was crushed with a maximum size of $25 \mathrm{~mm}$ from old runway concrete pavement at an air base reconstruction site. The RP was obtained with a maximum size of $20 \mathrm{~mm}$ by crushing the precast concrete (PC) culverts (see Figure 1). It should be noted that the first letter R from RA and RP refers to recycled coarse aggregate and the second letter denotes aggregate types used in this study where A is an arbitrary symbol while P was named since RP was manufactured from precast concretes.

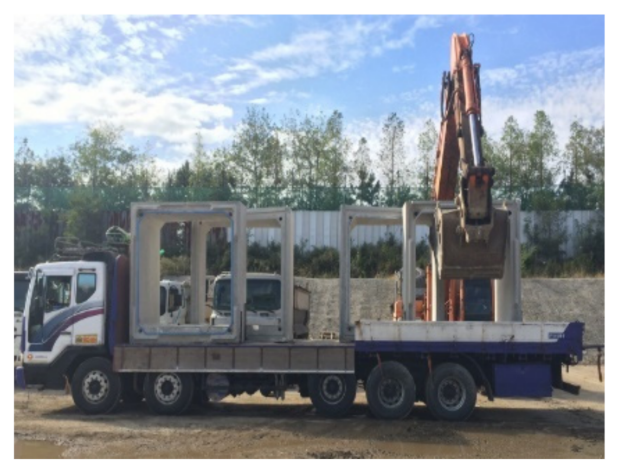

Figure 1. Recycled concrete aggregate (RCA) sources. 
The PC culverts had a compressive strength of $35 \mathrm{MPa}$ with a maximum aggregate of $20 \mathrm{~mm}$ and a water-cement ratio of $35 \%$ or lower according to the Korean Construction Specification [44] and were manufactured by steam curing.

\subsection{Aggregate Properties}

Table 1 shows the specific gravity, absorption rate, and residual mortar content (RMC) of the RCA and the specific gravity and absorption rate of the natural coarse aggregate and fine aggregate. The specific gravity and absorption ratio of the RA were 2.54 and $4.81 \%$, respectively. The specific gravity and absorption ratio of the RP were 2.60 and $2.62 \%$, respectively.

Table 1. Basic aggregate properties.

\begin{tabular}{cccccc}
\hline Test Items & RA & RP & NCA & Fine Aggregate 1 & Fine Aggregate 2 \\
\hline Specific gravity & 2.54 & 2.60 & 2.69 & 2.58 & 2.60 \\
Absorption rate (\%) & 4.81 & 2.62 & 0.54 & 0.52 & 0.95 \\
RMC & - & 20.0 & - & - & - \\
\hline
\end{tabular}

Crushed granite (which was the same source of aggregate previously used in PC culvers) was used as the natural coarse aggregate, and its specific gravity and absorption rate were 2.69 and $0.54 \%$, respectively. Natural river sand was used as the fine aggregate. RA and fine aggregate 1 were used in the first mix series, while RP and fine aggregate 2 were used in the second mix series. Figure 2 shows the particle size distribution for the RP, natural coarse aggregate (NCA), and fine aggregate 2, satisfying Korean standards.

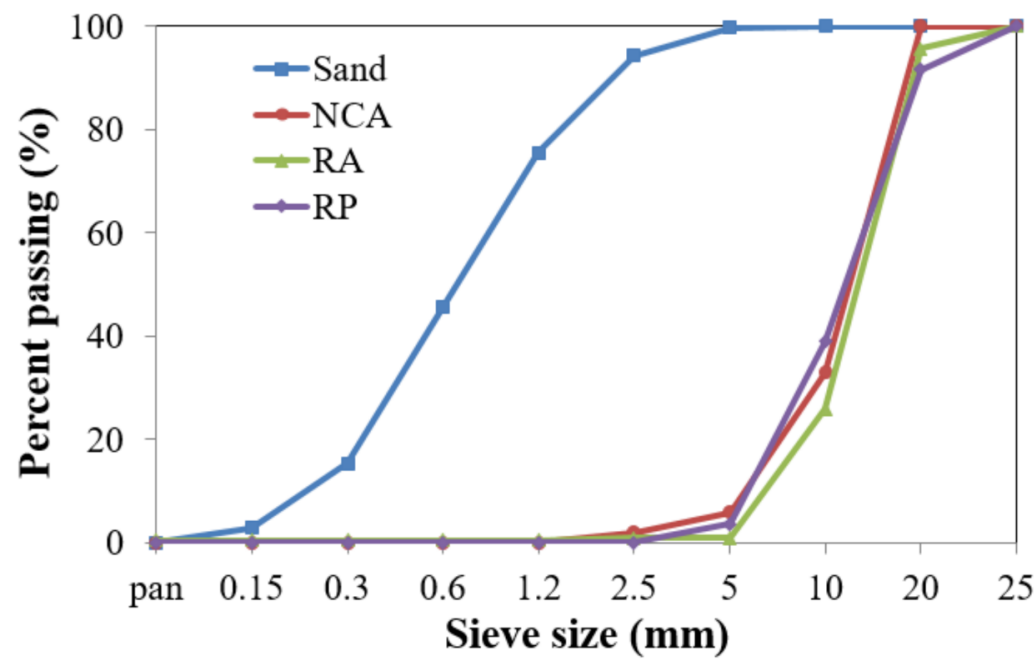

Figure 2. Aggregate gradation for RP, natural coarse aggregate (NCA), and fine aggregate 2.

In order to obtain the RMC value for $R P$, the heat treatment method proposed by Juan and Gutierrez [45] was used. After heating the prepared RCA samples for $2 \mathrm{~h}$ at $500{ }^{\circ} \mathrm{C}$ in an electric furnace, the heated samples were removed from the furnace and immersed in ice water to subject the samples to thermal shock and to separate the mortar. The RMC value was calculated by substituting the measured values in Equation (1). The RMC value was $20.0 \%$.

$$
\mathrm{RMC}=\left(\mathrm{W}_{\mathrm{RCA}}-\mathrm{W}_{\mathrm{OVA}}\right) / \mathrm{W}_{\mathrm{RCA}} \times 100
$$

where $\mathrm{W}_{\mathrm{RCA}}$ is the weight of the RCA dried in an oven dryer after first collecting the samples and $W_{\text {OVA }}$ is the weight of the original virgin aggregate (OVA) dried in an oven dryer after removing residual mortar. 


\subsection{Cement Paste Dissociation Agent}

The cement paste dissociation agent (CPDA) used in this study was a product composed of $\mathrm{SiO}_{2}, \mathrm{CaO}, \mathrm{NaCl}, \mathrm{NaNO}_{3}, \mathrm{Na}_{2} \mathrm{SO}_{4}$, and $\mathrm{K}_{2} \mathrm{CO}_{3}$. The chemical equations below explain the additional hydration reaction of calcium hydroxide from the cement and the CPDA [46]. Free calcium oxide of cement forms calcium hydroxide when mixed with water. Then, calcium hydroxide takes part in the reactions with the second and forth components to the left in the following equations, which are the main components of the CPDA to further form inorganic crystallization or ettringite around old ITZs or new ITZs.

$$
\begin{gathered}
3 \mathrm{Ca}(\mathrm{OH})_{2}+6 \mathrm{NaCl}+30 \mathrm{H}_{2} \mathrm{O}+\left(3 \mathrm{CaOAl}_{2} \mathrm{O}_{3}\right) \Rightarrow 3\left(\mathrm{CaOAl}_{2} \mathrm{O}_{3} \mathrm{CaCl}_{2} 10 \mathrm{H}_{2} \mathrm{O}\right)+6 \mathrm{NaOH} \\
3 \mathrm{Ca}(\mathrm{OH})_{2}+6 \mathrm{NaNO}_{3}+32 \mathrm{H}_{2} \mathrm{O}+\mathrm{Ca}_{3}\left(\mathrm{AlO}_{3}\right)_{2} \Rightarrow 3 \mathrm{Ca}_{3}\left(\mathrm{AlO}_{3}\right)_{2} 3 \mathrm{Ca}\left(\mathrm{NO}_{3}\right)_{2} 32 \mathrm{H}_{2} \mathrm{O}+6 \mathrm{NaOH} \\
3 \mathrm{Ca}(\mathrm{OH})_{2}+3 \mathrm{Na}_{2} \mathrm{SO}_{4}+31 \mathrm{H}_{2} \mathrm{O}+\mathrm{Ca}_{3}\left(\mathrm{AlO}_{3}\right)_{2} \Rightarrow 3\left(\mathrm{CaOAl}_{2} \mathrm{O}_{3}\right)_{2} \mathrm{CaSO}_{4} 31 \mathrm{H}_{2} \mathrm{O}+6 \mathrm{NaOH}
\end{gathered}
$$

As a percentage of cement, $1.25 \%$ CPDA powder was recommended for conventional cement concretes by the CPDA manufactured company [46]. However, in this study, to coat the weak parts of old ITZs in the RCA concrete, 2.5\% CPDA powder as a cement percentage, which is two times higher than the recommended dosages, was selected. Thus, for a preliminary test program (first mix series in Table 2), 0, 2.5, and 5\% CPDA powder as a percentage of cement amounts were added in RCA concrete mixes. The test results from Section 4.1 showed that the addition of $2.5 \%$ CPDA as chemical admixtures in the RCA concrete mixes helps improve compressive strength, flexural strength, and elastic modulus properties. Thus, in the main test program (second mix series in Table 2), $300 \mathrm{~g}$ of CPDA was diluted in $1 \mathrm{~L}$ of water instead of powder but with the same dosage and sprayed on the RCA surface as shown in Figure 3. The coated RCAs were poured in a pan and covered

\begin{tabular}{|c|c|c|c|c|c|c|c|c|c|c|c|c|}
\hline \multirow{2}{*}{ Test Series } & \multirow{2}{*}{ Mix } & \multirow{2}{*}{$\mathrm{W} / \mathrm{C}$} & \multirow{2}{*}{ S/a } & \multirow{2}{*}{ RCA wt \% } & \multicolumn{8}{|c|}{ Mix Proportions $\left(\mathrm{kg} / \mathrm{m}^{3}\right)$} \\
\hline & & & & & $\mathbf{W}$ & $\mathrm{C}$ & $S$ & F/A & NCA & RCA & CPDA & Admixture \\
\hline \multirow{3}{*}{1} & CRA-0 & 0.37 & 38.9 & 100 & 138 & 370 & 695 & - & - & 1093 & 0 & - \\
\hline & CRA-2.5 & 0.37 & 38.9 & 100 & 138 & 370 & 695 & - & - & 1093 & 9.25 & - \\
\hline & CRA-5 & 0.37 & 38.9 & 100 & 138 & 370 & 695 & - & - & 1093 & 18.5 & - \\
\hline \multirow{9}{*}{2} & $\mathrm{CNC}$ & 0.36 & 39.1 & 0 & 158 & 396 & 675 & 44.0 & 1051 & 0 & - & 2.56 \\
\hline & CRP-a & 0.36 & 40.4 & 25 & 158 & 396 & 694 & 44.0 & 767 & 256 & - & 2.49 \\
\hline & CRP-b & 0.36 & 41.7 & 50 & 158 & 396 & 712 & 44.0 & 499 & 498 & - & 2.49 \\
\hline & CRP-aS & 0.36 & 40.4 & 25 & 158 & 396 & 694 & 44.0 & 767 & 256 & - & 2.49 \\
\hline & CRP-bS & 0.36 & 41.7 & 50 & 158 & 396 & 712 & 44.0 & 499 & 498 & - & 2.49 \\
\hline & ERP-a & 0.36 & 37.0 & 25 & 152 & 380 & 648 & 42.3 & 830 & 276 & - & 2.60 \\
\hline & ERP-b & 0.36 & 34.6 & 50 & 145 & 363 & 619 & 40.3 & 584 & 583 & - & 2.61 \\
\hline & ERP-aS & 0.36 & 37.0 & 25 & 152 & 380 & 648 & 42.3 & 830 & 276 & - & 2.74 \\
\hline & ERP-bS & 0.36 & 34.6 & 50 & 145 & 363 & 619 & 40.3 & 584 & 583 & - & 2.62 \\
\hline
\end{tabular}
with plastic for curing for 2 days. Then, they were used in the concrete mixture.

Table 2. Concrete mixture designs and material quantities.

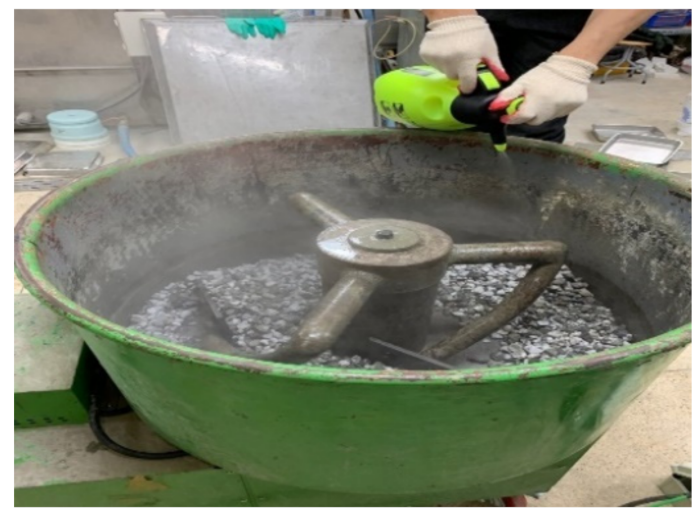

Figure 3. Spray coating RCAs. 


\section{Experimental Tests \\ 3.1. Mix Design}

In this experiment, type I Portland cement was used with a specific gravity of 3.15 and specific surface area of $3380 \mathrm{~cm}^{2} / \mathrm{g}$. The chemical admixture used in this experiment was an air entraining and water reducing agent solution. All of the aggregates were prepared in a saturated surface-dry condition.

Two series of mixes were prepared and tabulated in Table 2. The first series of mixes were designed in order to investigate the optimal amounts of cement paste dissociation agent (CPDA) powder. In the nomenclature from the first mix series, the numbers denote CPDA contents as a percentage of cement amounts.

The second series of mixes were then designed to find whether coating the RCAs with CPDA solution is an effective way to improve the durability properties such as drying shrinkage and chloride penetration resistance as well as mechanical strength properties of recycled aggregate concrete (RAC). This mix series involved nine mixtures. The conventional American Concrete Institute (ACI) mixing method and the equivalent mortar volume (EMV) mixing method were used. In the nomenclature, first, $\mathrm{C}$ and $\mathrm{E}$ in mix identification denote conventional and equivalent mix design, respectively. Next, $\mathrm{R}$ and $\mathrm{N}$ denote natural coarse aggregate and RCA, respectively. Thirdly, A refers to type A aggregate while $\mathrm{P}$ refers to aggregate manufactured from precast concretes. Fourthly, $-\mathrm{a}$ and $-\mathrm{b}$ refer to the $25 \%$ and $50 \%$ RCA replacement ratios per total coarse aggregate, respectively. Lastly, S used in the mixture nomenclature refers to the use of spray coating of the recycled concrete aggregate (RCA) surface in the mixture.

A pan mixer that could perform $60 \mathrm{~L}$ volume mixing was available in a research laboratory from Hongik University in Sejong, Korea, which is where the experimentation was conducted. First, the coarse aggregate and fine aggregate were poured in the mixer and mixed together for around $30 \mathrm{~s}$. Then, cement was added and mixed for $30 \mathrm{~s}$. Afterwards, the admixture was diluted sufficiently in water and added to the mixture for additional mixing for around $2 \mathrm{~min}$.

\subsection{Specimen Preparation}

The specimens for concrete compressive strength measurement were prepared using a $100 \mathrm{~mm} \times 200 \mathrm{~mm}$ plastic mold following a predetermined method [47]. The fabricated specimens were removed from the mold after $24 \mathrm{~h}$ and moist cured at approximately $20 \pm 2{ }^{\circ} \mathrm{C}$ until the compressive strength testing. Three specimens were tested for each mixture, and their average values were calculated.

Drying shrinkage experiments were performed using a dial gauge, as suggested by KS (Korean Standards) F 2424 [48], which is equivalent to ASTM (American Society for Testing and Materials) C 157-08 [49]. Two rectangular specimens with $100 \times 100 \times 400 \mathrm{~mm}$ were prepared for each mixture. The drying shrinkage strain was measured by the dial gauge. The specimens were kept inside an environmental chamber, which was controlled at $20^{\circ} \mathrm{C}$ and $60 \%$ Relative Humidity (RH). Figure 4 shows a schematic diagram and experimental specimens with the dial gauges installed.

In order to test the chloride ion penetration resistance, three cylindrical specimens with a $100 \mathrm{~mm}$ diameter and $200 \mathrm{~mm}$ height were prepared, followed by fabrication into disc specimens of $50 \mathrm{~mm}$ thickness in accordance with ASTM C 1202 [50]. The prepared disc specimens were placed in a vacuum state maintained for $3 \mathrm{~h}$; then, the specimens were immersed in distilled water for $18 \mathrm{~h}$ to fulfill the saturation state pretreatment. For the $100 \mathrm{~mm}$ diameter and $50 \mathrm{~mm}$ thickness specimens, the cathode was filled with $3 \% \mathrm{NaCl}$ aqueous solution and the anode was filled with $0.3 \mathrm{M} \mathrm{NaOH}$ aqueous solution followed by the application of $60 \mathrm{~V}$ for $6 \mathrm{~h}$. Figure 5 shows a schematic diagram for the Rapid Chloride Penetration Test (RCPT) setup. After the initial current measurement, the passing current value was measured in 30-min intervals and the total passed charge was calculated using Equation (5).

$$
Q=900\left(I_{0}+2 I_{30}+2 I_{60}+\cdots+2 I_{300}+2 I_{330}+I_{360}\right)
$$


where $Q$ refers to the total passed charge and $I_{n}$ refers to the current at $n$ minutes.

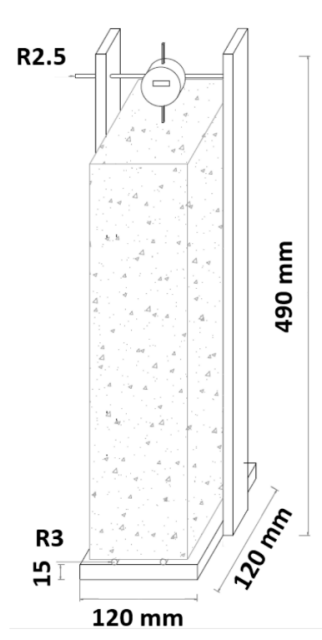

(a)

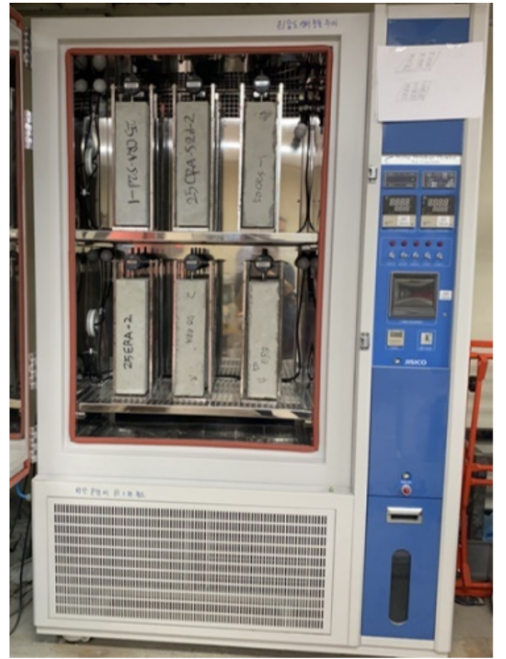

(b)

Figure 4. Experimental specimens with a dial-gauge installed: (a) schematic diagram and (b) picture.

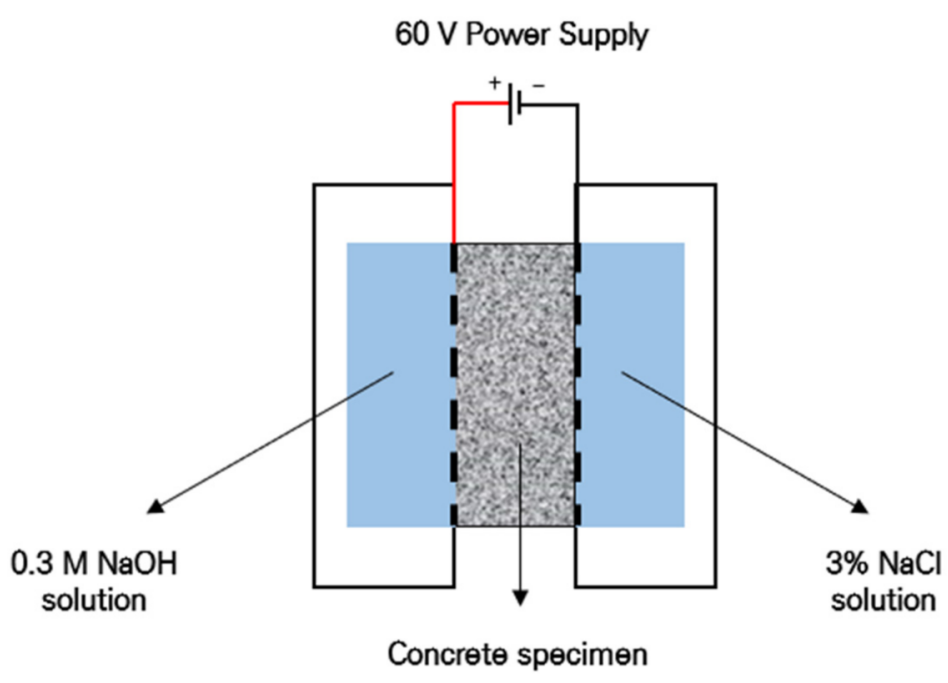

Figure 5. Chloride ion penetration resistance test setup.

\section{Experimental Test Results}

\subsection{Preliminary Test Results from First Mix Series}

Figure 6 shows average mechanical concrete strength properties such as compressive strength, flexural strength, and elastic modulus with error bars of the first mix series. In Figure $6 \mathrm{a}$, the compressive strengths increased by $32 \%$ and $24 \%$ at 7 and 28 days, respectively, in CRA-2.5 mix compared to CRA-0 mix (control specimen). On the other hand, the compressive strengths in CRA- 5 mix decreased by $27 \%$ and $24 \%$ at 7 and 28 days, respectively. The flexural strength test results showed a similar pattern to the compressive strength test results. The flexural strengths increased by $56 \%$ and $18 \%$ at 7 and 28 days, respectively, in CRA-2.5 mix compared to the control mix, whereas the flexural strengths in CRA- 5 mix decreased by $21 \%$ and $3 \%$ at 7 and 28 days, respectively. Figure $6 c$ shows the elastic modulus of the concrete test results at 28 days. In a similar manner to the compressive and flexural strength test results, elastic modulus increased by 3\% in CRA-2.5 mix but decreased by $9 \%$ in CRA- 5 mix compared to the control specimen. Thus, it appears that the addition of $2.5 \%$ of cement paste dissociation agent (CPDA) in the recycled concrete aggregate (RCA) concrete mixes helps improve the mechanical strength properties. 


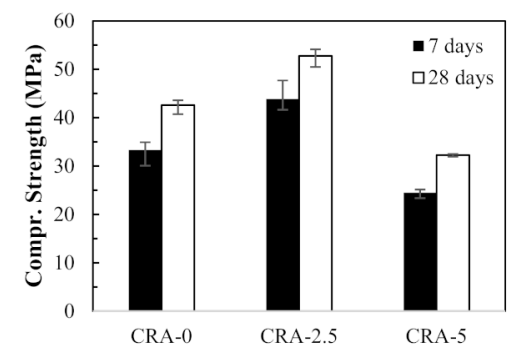

(a)

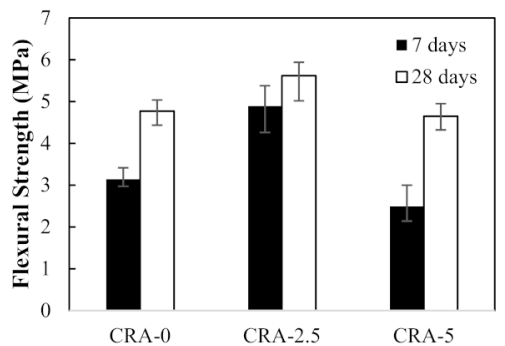

(b)

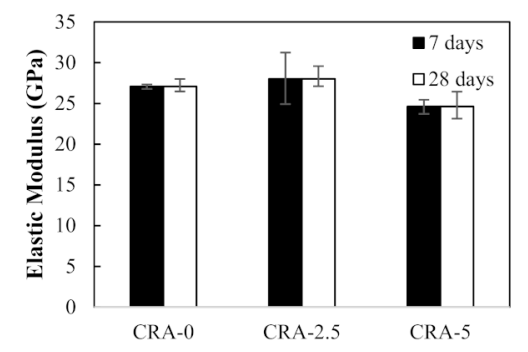

(c)

Figure 6. Mechanical strength results of first mix series: (a) compressive strength, (b) flexural strength, and (c) elastic modulus.

\subsection{Test Results from Second Mix Series \\ 4.2.1. Fresh and Hardened Properties}

It is commonly accepted that concrete durability is thoroughly related to fresh and hardened properties. Table 3 presents the measured fresh and hardened concrete properties from the second mix series. Generally, concrete, which is prepared with workable slump and proper air content and is compacted with high density, is expected to be durable with reasonable compressive strength. It was observed from Table 3 that all RCA concrete mixes proportioned with the conventional mix design method and the equivalent mortar volume (EMV) design method were found to be workable, with their slump ranging between 150 and $160 \mathrm{~mm}$. The air contents of all the mixes were almost identical, ranging from $3.9 \%$ to $4.2 \%$. Thus, it can be inferred that slump or air content of RCA concretes from the second mix series does not affect the mechanical strength or durability of RCA concretes.

Table 3. Fresh and hardened properties of the mixes.

\begin{tabular}{ccccccc}
\hline \multirow{2}{*}{ Mix iD } & \multicolumn{3}{c}{ Fresh Property } & \multicolumn{2}{c}{ Hardened Property } \\
\cline { 2 - 6 } & $\begin{array}{c}\text { Slump } \\
(\mathbf{m m})\end{array}$ & $\begin{array}{c}\text { Air Content } \\
\mathbf{( \% )}\end{array}$ & $\begin{array}{c}\text { Density } \\
\left(\mathbf{k g} / \mathbf{m}^{\mathbf{3}}\right)\end{array}$ & $\begin{array}{c}\text { Density } \\
\left(\mathbf{k g} / \mathbf{m}^{\mathbf{3}}\right)\end{array}$ & $\begin{array}{c}\text { Compressive Strength } \\
\mathbf{( M P a )}\end{array}$ & $\begin{array}{c}\text { Coefficient of Variation } \\
\mathbf{( \% )}\end{array}$ \\
\hline CNC & 155 & 3.9 & 2414 & 2334 & 32.2 & 3.00 \\
CRP-a & 150 & 4.0 & 2333 & 2428 & 31.6 & 2.60 \\
CRP-b & 155 & 4.1 & 2360 & 2332 & 30.8 & 3.67 \\
CRP-aS & 155 & 4.0 & 2364 & 2301 & 30.3 & 4.84 \\
CRP-bS & 150 & 4.2 & 2389 & 2389 & 31.6 & 2.25 \\
ERP-a & 160 & 4.1 & 2294 & 2267 & 27.7 & 3.00 \\
ERP-b & 150 & 4.2 & 2336 & 2336 & 30.5 & 2.68 \\
ERP-aS & 155 & 4.1 & 2354 & 2306 & 30.1 & 2.53 \\
ERP-bS & 150 & 4.3 & 2314 & 2249 & 24.8 & 2.48 \\
\hline
\end{tabular}

Table 3 summarizes density values at the fresh state and hardened state. While there were some deviations depending on the degree of aggregate coating, RCA substitution ratio, and fresh or hardened state, it seems that the densities of the ERP mixes are 1-2\% lower values compared to that of the CNC and CRP mixes. 
The compressive strength values at 28 days are represented in Table 3. Excluding ERP-a and ERP-bS, the compressive strength values were similar, at around 30.1-32.2 MPa. It was predicted $[14,15]$ that the concrete that uses the EMV mixing method would exhibit higher strength than concrete that uses the conventional volume mixing method. However, in the case of the RCA used in this mixture, its quality was excellent, with a specific gravity of 2.60 and absorption rate of $2.62 \%$, resulting in favorable strength even when the conventional ACI volume mixing method was used.

Figure 7 shows the average Young's modulus of the concrete samples at 28 days. All the elastic modulus values ranged from 26.3-27.7 GPa within 5\% difference, regardless of different mixing methods or use of coating treatment method.

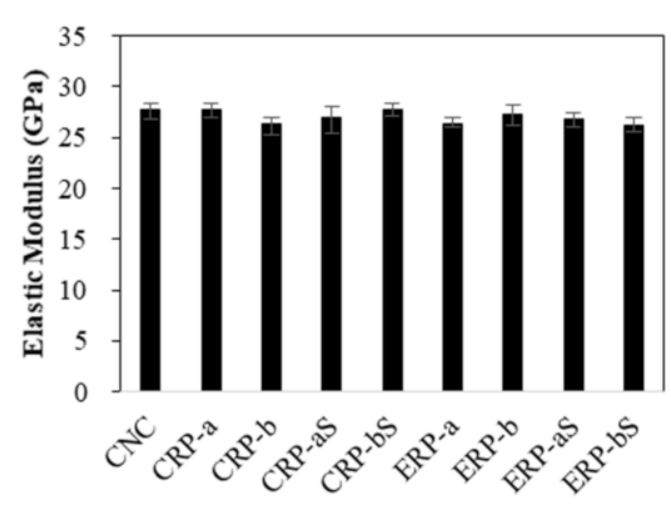

(a)

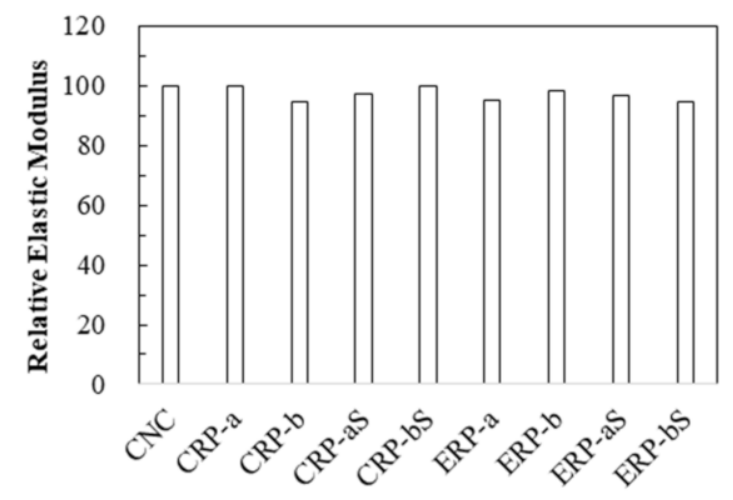

(b)

Figure 7. Elastic modulus and relative values: (a) elastic modulus and (b) relative elastic modulus.

\subsubsection{Drying Shrinkage}

The drying shrinkage test results are shown in Figure 8. Drying shrinkage tests were conducted for all the specimens initially for 111 days, as shown in Figure 8a. It must be noted that the initial wet curing period of 8 days instead of the standard wet curing period of 7 days was employed for the control specimen (CNC) and CRP specimens by malfunction of the environmental chamber. Therefore, it can be seen in Figure 8a that the ERP-a specimen produced higher drying shrinkage test values at early ages compared to the CRP specimens. However, previous researches $[5,9,15]$ revealed that the EMV mixing method yielded a drying shrinkage property of the RCA concrete lower than that of the RCA concrete mixed with the conventional mixing method. Therefore, to verify that this comparatively higher shrinkage value of the ERP at early stages becomes a gradually lower value than that of the CRP specimens, drying shrinkage strains of the CNC, CRP-a, CRP-b, and ERP-a specimens were further measured for 648 days, as shown in Figure $8 \mathrm{~b}$. The test results are subsequently discussed in terms of three influencing factors: (1) mix proportioning method, (2) with and without RCA coating treatment, and (3) RCA replacement ratio.

\section{Dependence of Mix Proportioning Method}

The effect of different mix proportioning methods on drying shrinkage was studied, and their average test results are plotted with error bars in Figure 9. First, as shown in Figure $9 \mathrm{a}$, the drying shrinkage values of CRP-a and ERP-a specimens were almost identical at 111 days, as mentioned before, but the drying shrinkage of the ERP-a specimen decreased by $4.6 \%$ at 648 days compared to that of CRP-a specimen. Likewise, in Figure $9 \mathrm{~b}-\mathrm{d}$, the drying shrinkage values of the ERP-aS, ERP-b, and ERP-bS specimens decreased by $5.1 \%$, $9.6 \%$, and $0.1 \%$ compared to those of the CRP-aS, CRP-b, and CRP-bS specimens at 111 days, respectively. Hence, a lower drying shrinkage of RCA concrete can be achieved using the EMV mix proportion method compared to the RCA concrete proportioned by the conventional mix design method. This was confirmed by Fathifazl et al. [5] that drying 
shrinkage is proportional to the total volume of the mortar and that the conventional RCA concrete mix contains a higher volume of mortar due to residual mortar.

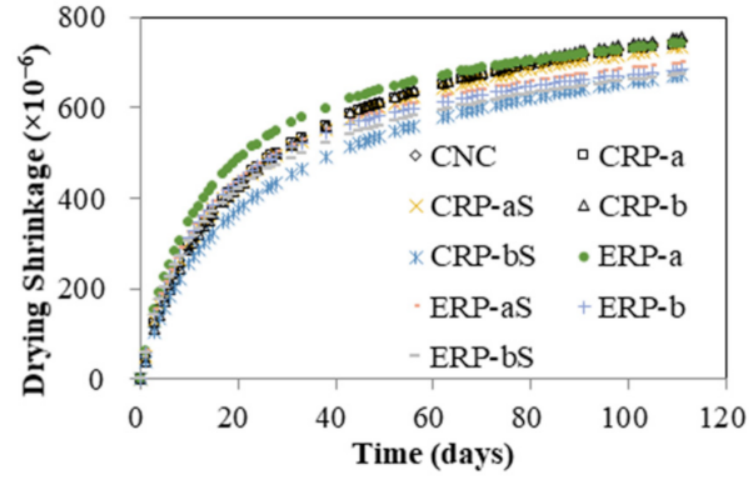

(a)

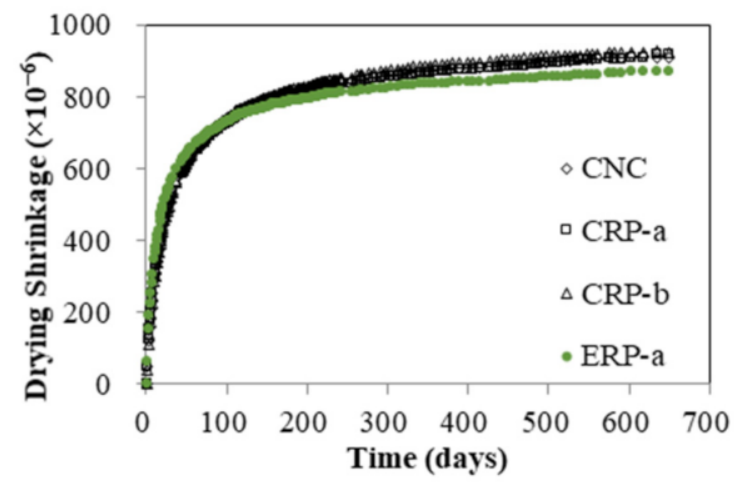

(b)

Figure 8. Drying shrinkage test results: (a) all specimens tested for 111 days and (b) some specimens tested for 648 days.

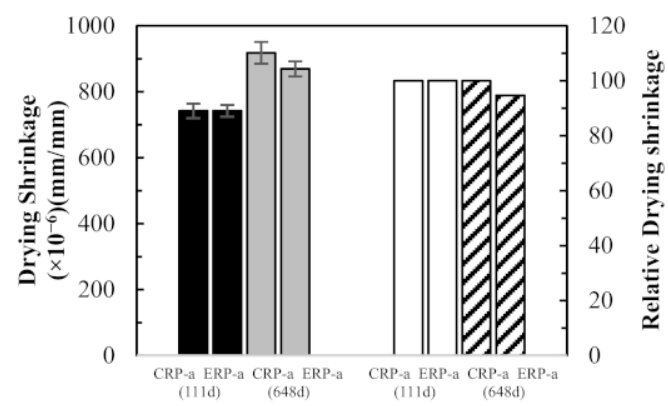

(a)

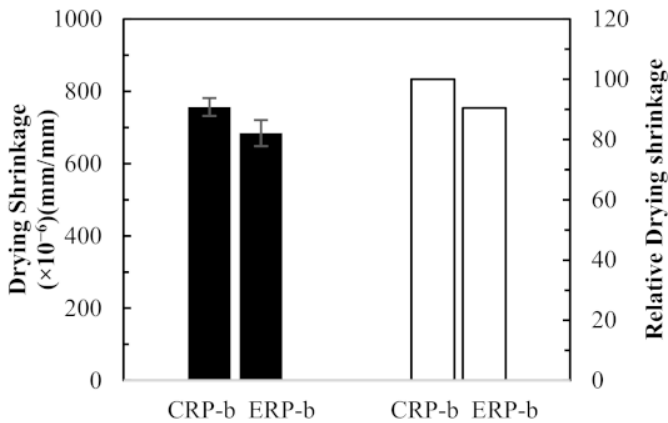

(c)

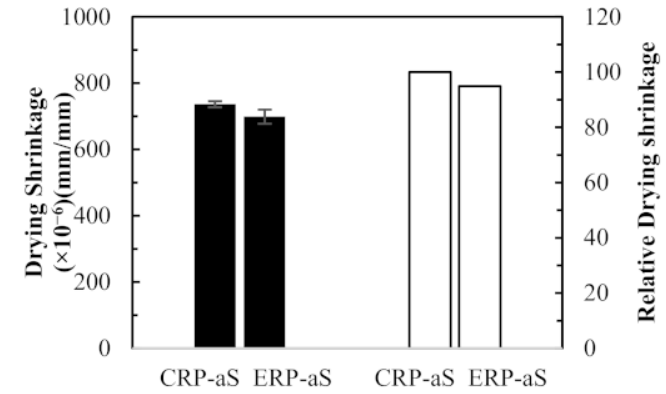

(b)

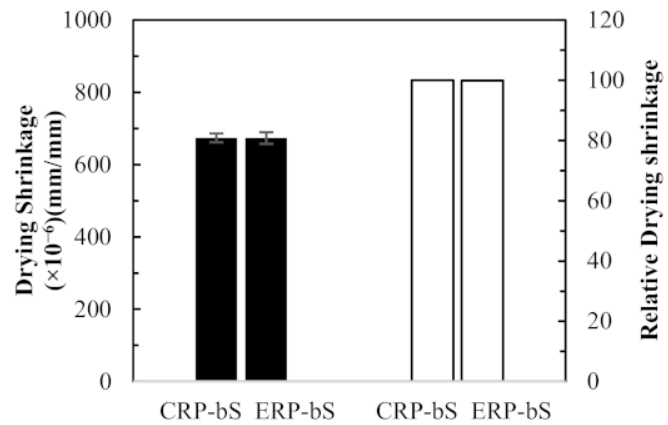

(d)

Figure 9. Concrete drying shrinkage results and relative values between different mix design method: (a) CRP-a versus ERP-a, (b) CRP-aS versus ERP-aS, (c) CRP-b versus ERP-b, and (d) CRP-bS versus ERP-bS.

\section{Dependence of Coating Treatment}

The effect of RCA coating on drying shrinkage was studied, and their average test results are plotted in Figure 10. Figure 10a-d show that the drying shrinkage values of CRP-aS, CRP-bS, ERP-aS, and ERP-bS mixes at 111 days decreased by $1 \%, 11 \%, 6 \%$, and $2 \%$, respectively, compared to those of CRP-a, CRP-b, ERP-a, and ERP-b. Thus, all the concrete specimens, which were mixed with coated RCA, represented better drying shrinkage performance than those mixed without RCA coating treatment, regardless of different mix proportioning methods and RCA replacement ratios. 


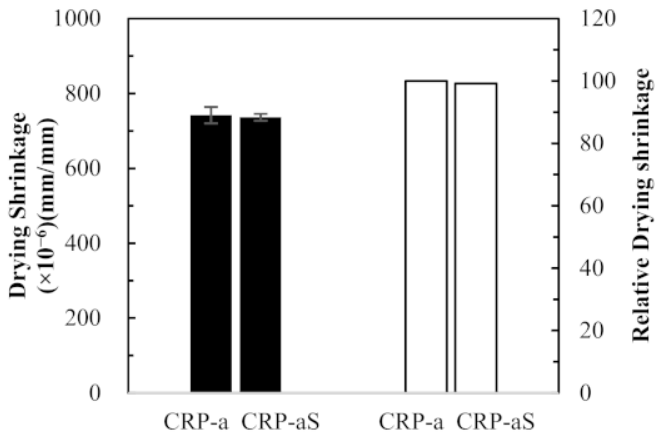

(a)

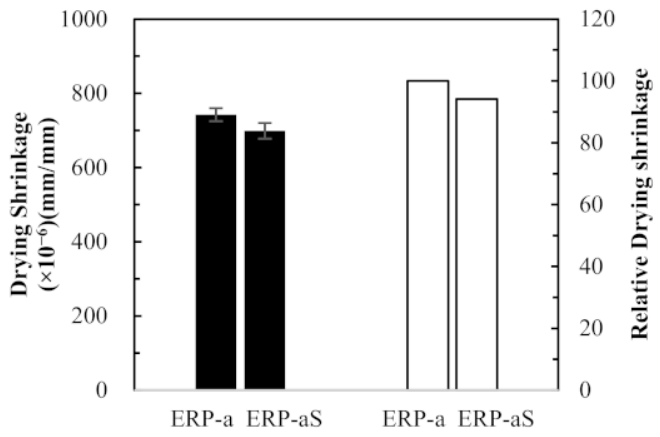

(c)

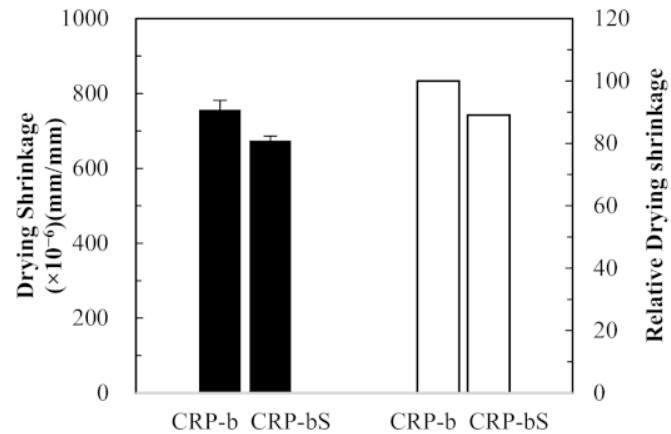

(b)

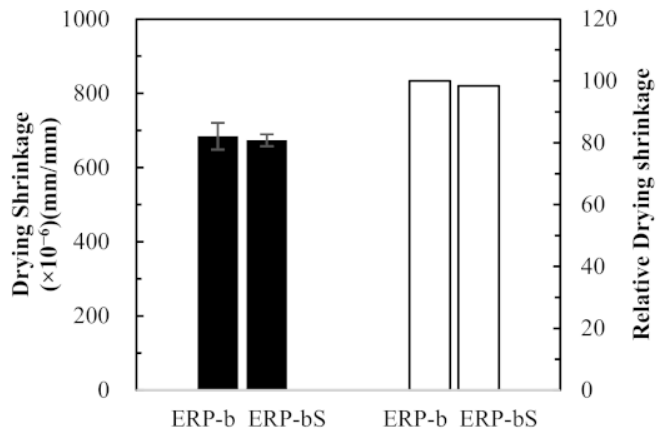

(d)

Figure 10. Concrete drying shrinkage results and relative values with and without recycled concrete aggregate coating treatment: (a) CRP-a versus CRP-aS, (b) CRP-b versus CRP-bS, (c) ERP-a versus ERP-aS, and (d) ERP-b versus ERP-bS.

\section{Dependence of RCA Replacement Ratio}

The test results were compared to investigate the effect of the RCA replacement ratios on the drying shrinkage of RCA concretes. In Figure 11a, compared to the drying shrinkage value of the CRP-a concrete specimen, which is made with $25 \%$ RCA replacement ratio, that of the CRP-b concrete specimen with 50\% RCA replacement ratio was increased marginally by $2 \%$ at 111 days. However, reversed test results were observed in Figure $11 \mathrm{~b}-\mathrm{d}$. In Figure 11b, CRP-bS specimens resulted in an $8.5 \%$ drop in concrete drying shrinkage compared to CRP-aS specimens. Although CRP-bS specimens were mixed with a 50\% RCA replacement ratio using the conventional mix proportioning method, double the amount of coated RCAs led to a drop in drying shrinkage value compared to CRP-aS specimens. It is generally accepted that more RCA replacement in concrete mix leads to inferior drying shrinkage performance. However, the little increase or reversed result of drying shrinkage in concrete made with double the amount of RCA replacement may be attributed to the good-quality RCA adopted in this study. In Figure 11c, an 8\% drop in concrete drying shrinkage of the ERP-b specimen was obtained with a 50\% RCA replacement ratio compared to that of the ERP-a specimen with a $25 \%$ RCA replacement ratio. It should be remembered that the drying shrinkage values of the EMV mixes are expected to be similar regardless of different RCA replacement ratios incorporated in the EMV mix design, as the total mortar is the same. In a similar manner, about a $4 \%$ decrease in drying shrinkage for the ERP-bS specimen was observed in Figure 11d compared to the ERP-aS specimen.

\subsubsection{Chloride Ion Penetration Resistance}

Figure 12 shows the chloride ion penetration resistance experiment results for the concrete specimens. In the same manner as in Section 4.2.2, the test results are subsequently discussed in terms of three influencing factors: (1) mix proportioning method, (2) with and without RCA coating treatment, and (3) RCA replacement ratio. 


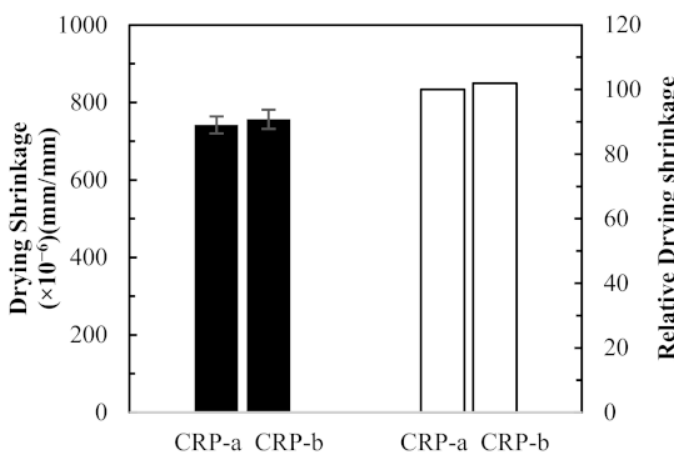

(a)

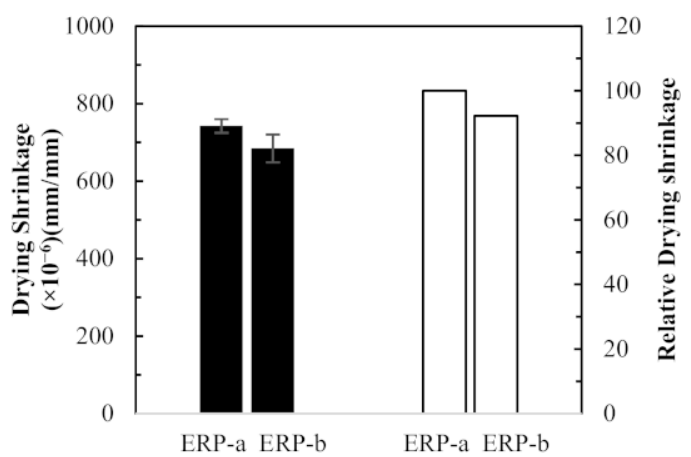

(c)

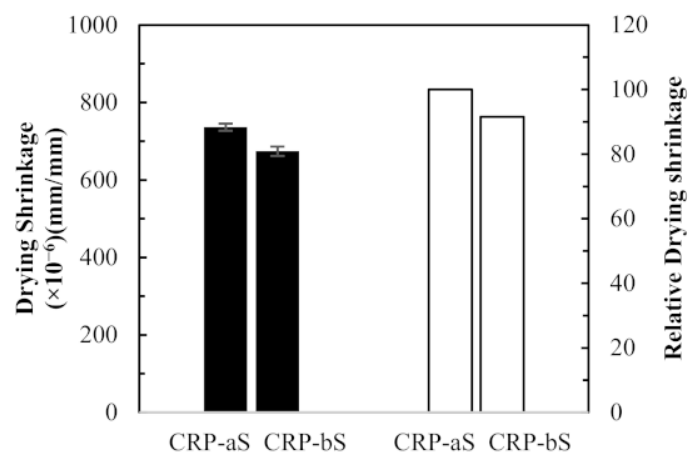

(b)

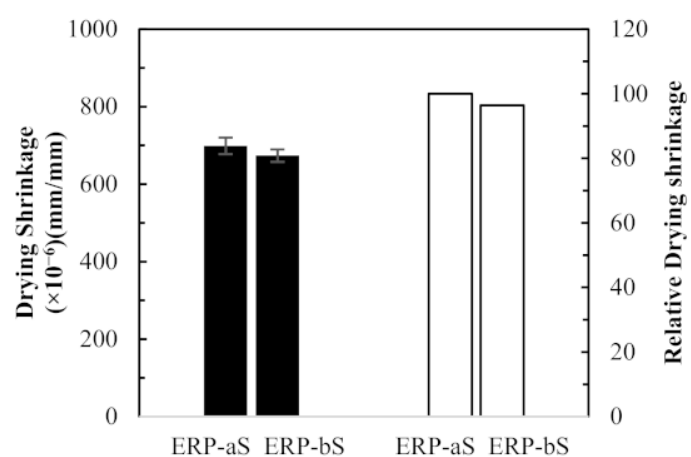

(d)

Figure 11. Concrete drying shrinkage results and relative values between different recycled concrete aggregate replacement ratios: (a) CRP-a versus CRP-b, (b) CRP-aS versus CRP-bS, (c) ERP-a versus ERP-b, and (d) ERP-aS versus ERP-bS.

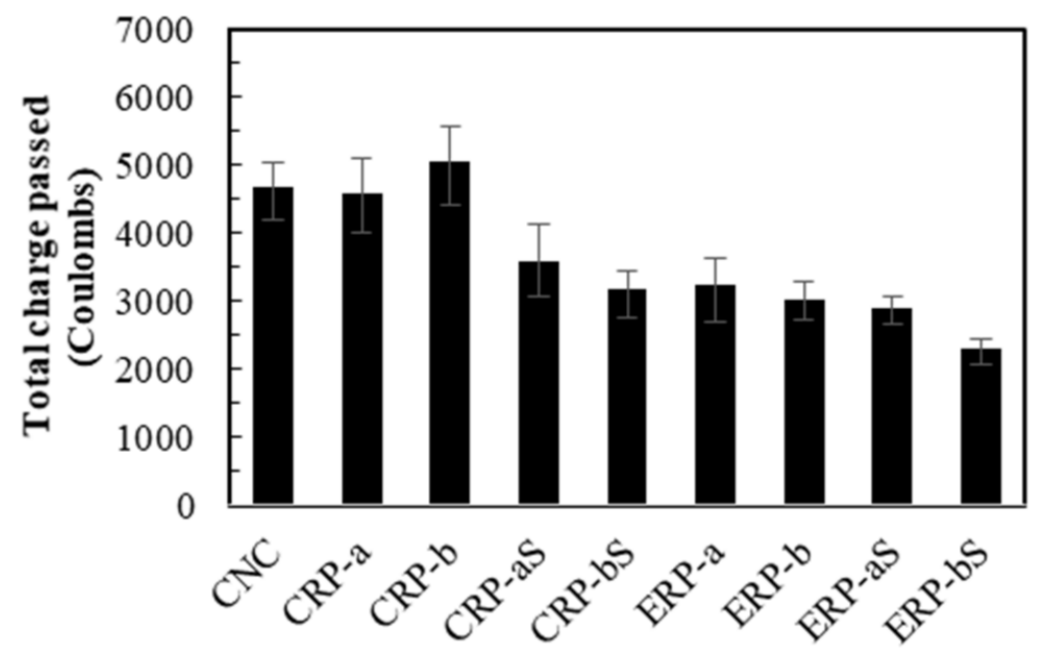

Figure 12. Chloride ion penetration resistance experiment results.

ASTM C 1202 [50] recommends the total charge passed between 2000 to $4000 \mathrm{C}$ to be a moderate condition for concrete specimens. From this recommendation, except for $\mathrm{CNC}, \mathrm{CRP}-\mathrm{a}$, and CRP-b, all other mixes in Figure 12 represented good resistance against the chloride ion penetration resistance. Thus, it may be said that the ERP mixes have unparalleled resistance regardless of RCA coating treatment, but combined with the RCA coating treatment, it produced the finest performance against chloride ion penetration. 


\section{Mix Proportioning Method}

The effect of different mix proportioning methods on chloride ion penetration resistance was studied and their Rapid Chloride Penetration Test (RCPT) results are plotted in Figure 13. In Figure 13a-d, the RCPT values of the ERP-a, ERP-aS, ERP-b, and ERP-bS specimens decreased remarkably by $30 \%, 19 \%, 40 \%$, and $28 \%$, compared to those of the CRP-a, CRP-aS, CRP-b, and CRP-bS specimens, respectively. In fact, the RCPT values for RCA concrete specimens proportioned by the EMV method were substantially lower than those of the specimens made of a mixture proportioned by the conventional method. Thus, it may be inferred that the RCPT values are related to the total mortar volume of the RCA concrete mix since the total mortar volume in the ERP mixes is reduced due to the residual mortar attached to the RCAs.

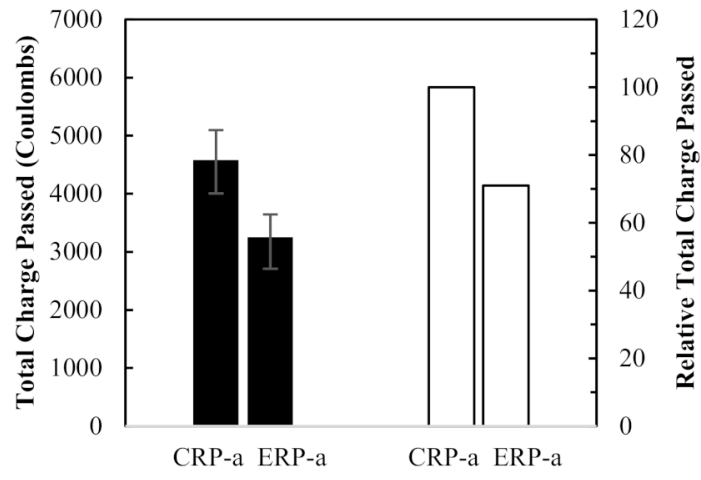

(a)

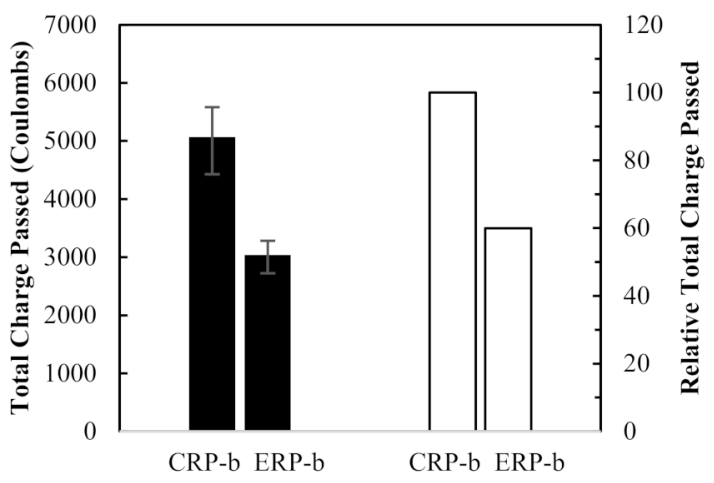

(c)

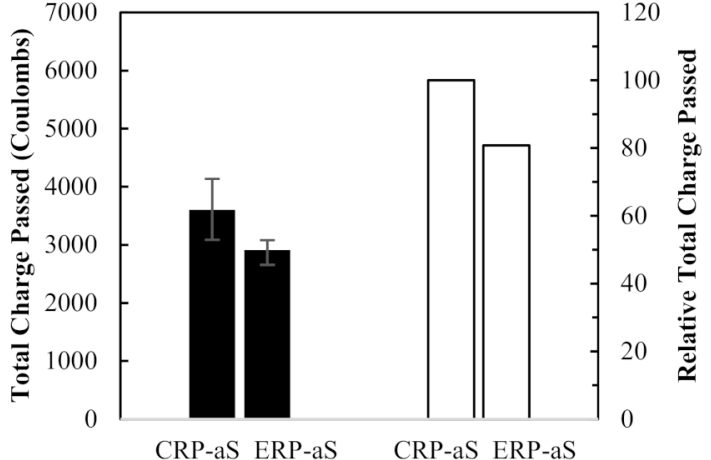

(b)

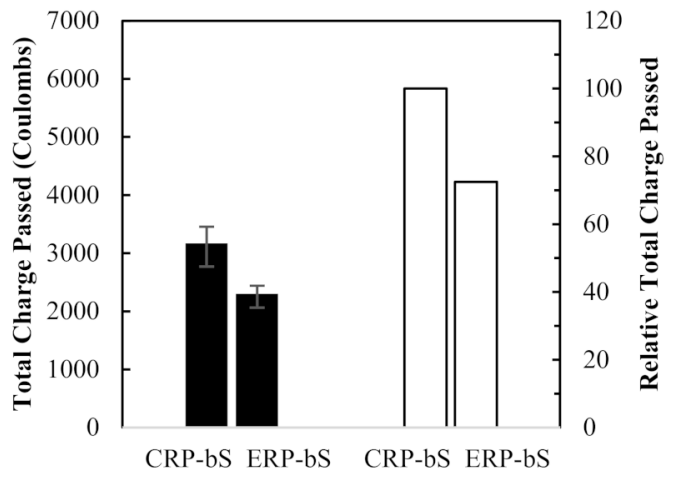

(d)

Figure 13. Rapid Chloride Penetration Test results and relative values between different mix design method: (a) CRP-a, (b) CRP-aS, (c) CRP-b, and (d) CRP-bS.

\section{Coating Treatment}

The effect of RCA coating on the RCPT results was studied, and their average test results are plotted in Figure 14. Figure 14a-d show that the RCPT values of CRP-aS, CRP-bS, ERP-aS, and ERP-bS mixes decreased by $21 \%, 37 \%, 10 \%$, and $24 \%$, respectively, compared to those of CRP-a, CRP-b, ERP-a, and ERP-b. Thus, all the concrete specimens, which were mixed with the coated RCAs, represented reduced RCPT values compared to those mixed without RCA coating treatment, regardless of different mix proportioning methods or RCA replacement ratios. In fact, implementing the RCA coasting treatment using the CPDA solution before concrete mixing resulted in better performance for drying shrinkage as well as chloride ion penetration resistance. 


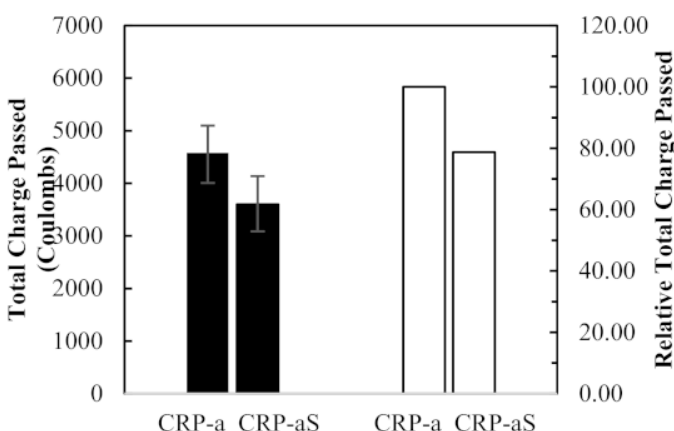

(a)

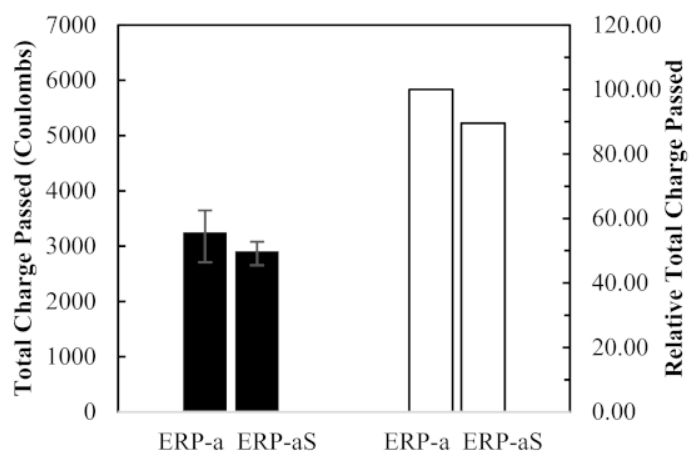

(c)

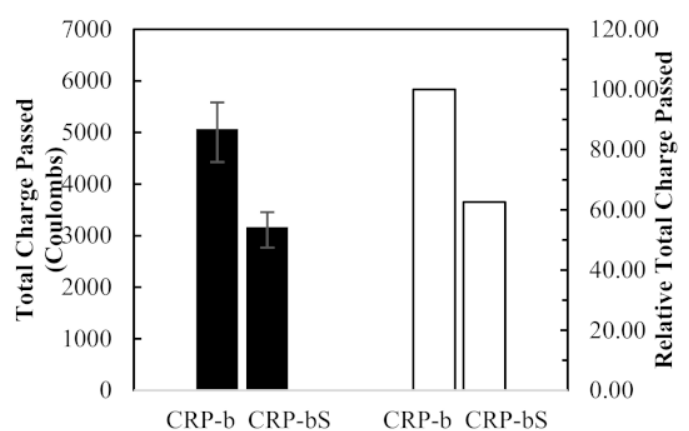

(b)

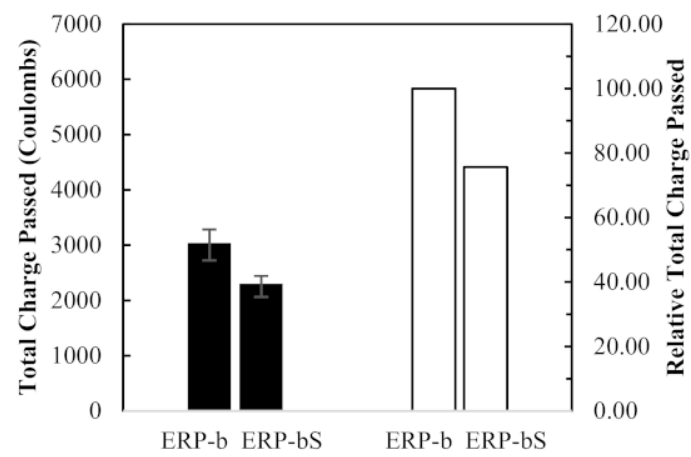

(d)

Figure 14. Rapid Chloride Penetration Test results and relative values between different mix design method with and without recycled concrete aggregate coating: (a) CRP-a, (b) CRP-b, (c) ERP-a, and (d) ERP-b.

\section{RCA Replacement Ratio}

The test results were compared to determine the effect of RCA replacement ratios on the RCPT values of RCA concretes, as shown in Figure 15. In Figure 15a, compared to the RCPT value of the CRP-a concrete specimen, which is made with $25 \%$ RCA replacement ratio, that of the CRP-b concrete specimen with 50\% RCA replacement ratio increased by $11 \%$. It is also widely accepted that more RCA replacement in concrete mix leads to inferior chloride ion penetration resistance. However, contrary test results were observed in Figure 15b-d. In Figure 15b, the CRP-bS specimens resulted in a 12\% drop in the RCPT value compared to CRP-aS specimens. Although CRP-bS specimens were mixed with $50 \%$ RCA replacement ratio, using the conventional mix proportioning method, double the amount of coated RCAs led to a drop in the RCPT value compared to CRP-aS specimens. In Figure 15c, a 6\% drop in the RCPT value of the ERP-b specimen was obtained with 50\% RCA replacement ratio compared to that of the ERP-a specimen with $25 \%$ RCA replacement ratio. As mentioned before, those two test values were supposed to be similar, regardless of different RAC replacement ratios, since their total mortar is the same. Likewise, about a $20 \%$ drop in the RCPT value for the ERP-bS specimen was observed in Figure 15d compared to ERP-aS specimen. Similar to the test results from Section 4.2.2 Drying Shrinkage, the reversed result of the RCPTs in concrete made with double the amount of RCA replacement except for CRP-a versus CRP-b may be attributed to the good-quality RCA adopted in this study. Further study on this effect is necessary.

\subsubsection{Micro Structural Analysis of RCA}

A scanning electronic microscope (SEM) was used to observe the microstructural characteristics of RCA concretes. In this study, CRP-b and CRP-bS samples only were tested to check whether the CPDA coating effect was seen in the image analysis. In Figure 16b, the darker area is the original virgin aggregate, while the lighter part in Figure $16 \mathrm{~b}$ is old mortar. The strip area between aggregate and old mortar is the interfacial transition zone 
(ITZ). It can be seen that the old ITZ in CRP-b (Figure 16a) is different from the old ITZ in CRP-bS (Figure 16b). The old ITZ width in Figure 16a ranges between 22 to $47 \mu \mathrm{m}$, while the old ITZ width in Figure 16b ranges between 7 to $11 \mu \mathrm{m}$. This implies that the coating effect of the CPDA can modify the microstructure of ITZs. Further research is needed to explore image analysis related to this topic.

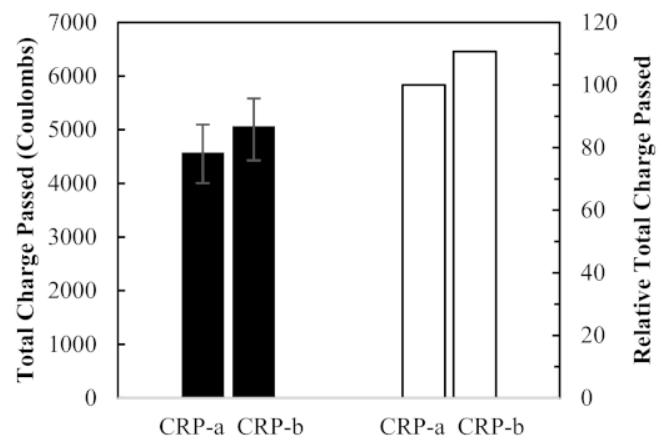

(a)

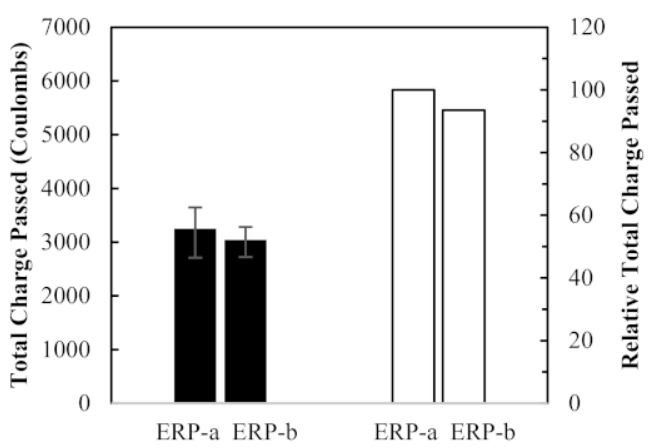

(c)

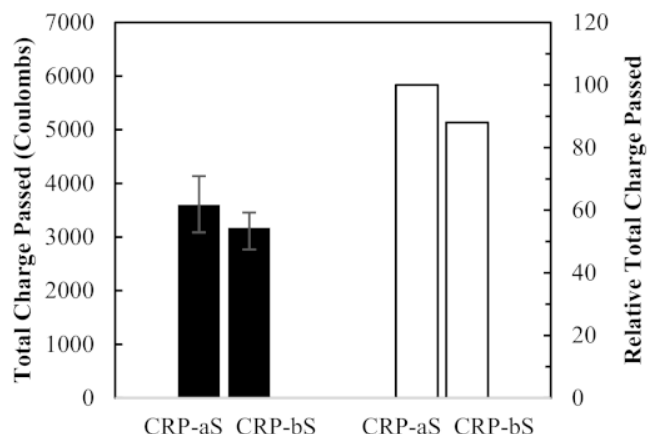

(b)

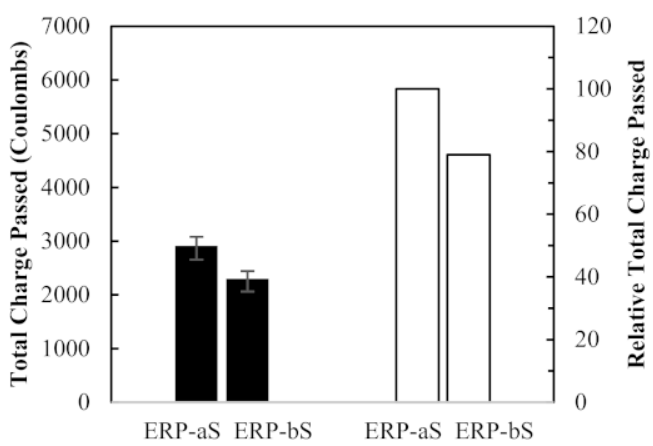

(d)

Figure 15. Rapid Chloride Penetration Test results and relative values between different recycled concrete aggregate replacement ratios: (a) CRP-a, (b) CRP-b, (c) ERP-a, and (d) ERP-b.

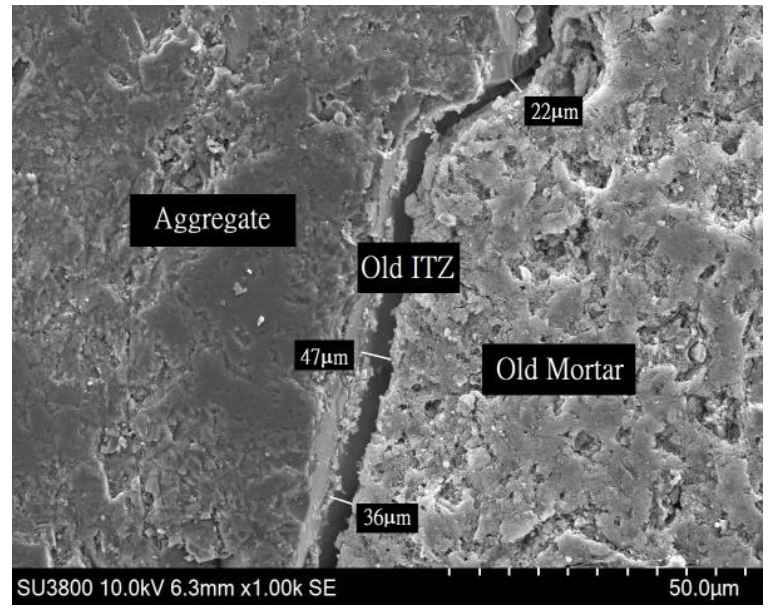

(a)

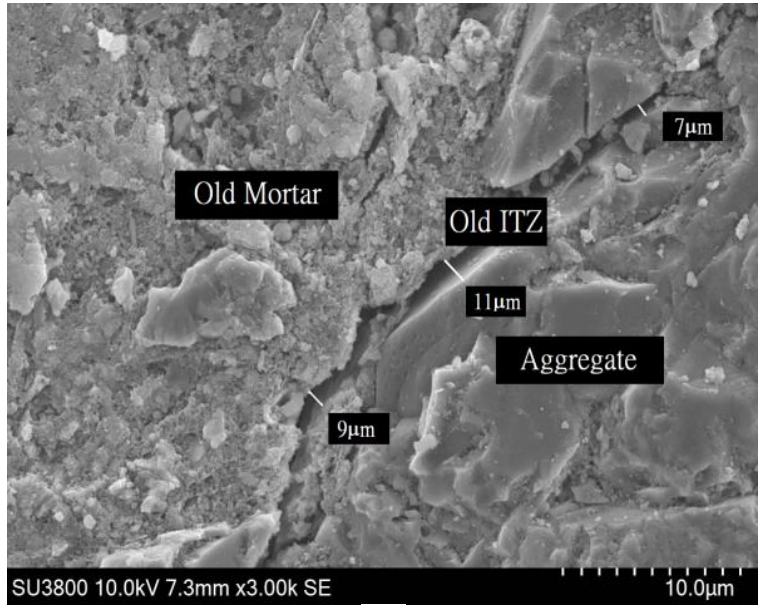

(b)

Figure 16. Scanning electronic microscope in the interfacial transition zone (ITZ) of different RCAs: (a) CRP-b and (b) CRP-bs.

\section{Conclusions}

In this study, recycled concrete aggregate (RCA) manufactured from precast concrete (PC) culvert was used to carry out durability experiments on concrete fabricated using 
the conventional ACI volume mixing method and the equivalent mortar volume (EMV) mixing method. Moreover, a cement paste dissociation agent (CPDA) was used to coat the RCA surface followed by curing to investigate the drying shrinkage and the chloride ion penetration resistances of the concrete coated at the RCA surface with CPDA compared with concrete that did not. The following conclusions were obtained from the experimental results.

1. From the preliminary test, it appears that the addition of $2.5 \%$ of CPDA in the RCA concrete mixes helps improve the mechanical strength properties such as compressive strength, flexural strength, and elastic modulus. The test results showed that about $24 \%, 18 \%$, and $3 \%$ increases were observed for compressive strength, flexural strength, and elastic modulus, respectively, at 28 days.

2. All RCA concretes mixed with coated RCA were found to be workable regardless of different mix methods, with the slump and air contents of all the mixes being almost identical. Additionally, all the concrete specimens that were mixed with the coated RCAs with CPDA solution had lower drying shrinkage values and RCPT (Rapid Chloride Penetration Test) values than those mixed without RCA coating treatment, regardless of different mix proportioning methods or RCA replacement ratios. The variation in compressive strength and density of the RCA concrete did not affect drying shrinkage or RCPT values.

3. This holds for the concrete specimens proportioned with the EMV method, regardless of different RCA replacement ratios. Especially, it may be inferred that the RCPT values are related to total mortar volume of RCA concrete mix since total mortar volume in the ERP mixes is reduced due to the residual mortar attached to the RCAs.

4. For the conventional RCA mixes, in comparison to test results from the $25 \%$ RCA replacement ratio, the little increase or reversed test result of drying shrinkage values and RCPT values in concrete made with 50\% RCA replacement ratio may be attributed to the good-quality RCA adopted in this study. Further study on this effect is necessary.

Author Contributions: Conceptualization, S.Y. and H.L.; methodology, S.Y. and H.L.; validation, S.Y.; formal analysis, H.L.; investigation, H.L.; resources, H.L.; data curation, S.Y. and H.L.; writingoriginal draft preparation, S.Y.; writing-review and editing, S.Y.; supervision, S.Y.; project administration, H.L.; funding acquisition, S.Y. All authors have read and agreed to the published version of the manuscript.

Funding: This research was funded by the Ministry of Land, Infrastructure, and Transport (MOLIT) and the Korea Agency for Infrastructure Technology Advancement (KAIA), grant number 21POQWB152690-03.

Institutional Review Board Statement: Not applicable.

Informed Consent Statement: Not applicable.

Data Availability Statement: The data presented in this study are available on request from the corresponding author.

Conflicts of Interest: The authors declare no conflict of interest.

\section{References}

1. Rahid, K.; Razzaq, A.; Dhmad, M.; Rashid, T.; Tariq, S. Experimental and analytical selection of sustainable recycled concrete with ceramic waste aggregate. Constr. Build. Mater. 2017, 154, 829-840. [CrossRef]

2. Szelag, M.; Zegardło, T.; Andrzejuk, W. The use of fragmented, worn-out car side windows as an aggregate for cementitious composites. Materials 2019, 12, 1467. [CrossRef]

3. Ramdani, S.; Guettala, A.; Benmalek, M.; Agular, J. Physical and mechanical performance of concrete made with waste rubber aggregate, glass powder and silica sand powder. J. Build. Eng. 2019, 21, 302-311. [CrossRef]

4. Yang, S. A feasibility study of wood-plastic composite paver block for basic rest areas. J. Korean Wood Sci. Technol. 2019, 47, 51-65.

5. Fathifazl, G. Structural Performance of Steel Reinforced Recycled Concrete Members. Ph.D. Thesis, Carleton University, Ottawa, ON, Canada, January 2008. 
6. Snyder, M. Recycling concrete pavements. In Proceedings of the ACPA Pennsylvania Chapter Presentation, Harrisburg, PA, USA, 27 January 2010.

7. Thomas, C.; Setien, J.; Polanco, J. Structural recycled aggregate concrete made with precast wastes. Constr. Build. Mater. 2016, 114, 536-546. [CrossRef]

8. Andal, J.; Shehate, M.; Zacarias, P. Properties of concrete containing recycled concrete aggregate of preserved quality. Constr. Build. Mater. 2016, 125, 842-855. [CrossRef]

9. Yang, S.; Lim, Y. Mechanical strength and drying shrinkage properties of RCA concretes produced from old railway concrete sleepers using by a modified EMV method. Constr. Build. Mater. 2018, 185, 499-507. [CrossRef]

10. Shi, X.; Mukhopadhyay, A.; Zollinger, D. Sustainability assessment for portland cement concrete pavement containing reclaimed asphalt pavement aggregates. J. Clean. Prod. 2018, 192, 569-581. [CrossRef]

11. Tam, V.; Tam, C. Assessment of durability of recycled aggregate concrete produced by two-stage mixing approach. J. Mater. Sci. 2007, 42, 3592-3602. [CrossRef]

12. Sicakova, A.; Urban, K. The influence of discharge time, kind of additive and kind of aggregate on the properties of three-stage mixed concrete. Sustainability 2018, 10, 3862. [CrossRef]

13. Abousnina, R.; Manalo, A.; Ferdous, W.; Lokugel, W.; Benabed, B.; Al-Jabri, W. Characteristics, strength development and microstructure of cement mortar containing oil-contaminated sand. Constr. Build. Mater. 2020, 252, 119155. [CrossRef]

14. Fathifazl, G.; Abbas, A.; Razaqpur, A.G.; Isgor, O.B.; Fournire, B.; Foo, S. New mixture proportioning method for concrete made with coarse recycled concrete aggregate. J. Mater. Civ. Eng. ASCE 2009, 21, 601-611. [CrossRef]

15. Yang, S.; Lee, H. Mechanical properties of recycled aggregate concrete proportioned with modified equivalent mortar volume method for paving applications. Constr. Build. Mater. 2017, 136, 9-17. [CrossRef]

16. Gupta, P.; Khaudhair, Z.; Ahuja, A. A new method for proportioning recycled concrete. Struct. Concr. 2016, 4, 677-687. [CrossRef]

17. Kisku, N.; Raijand, P.; Panda, S.; Nayak, S.; Pandey, V. Development of durable concrete from C\&D waste by adopting identical mortar volume method in conjunction with two-stage mixing procedure. Constr. Build. Mater. 2020, $256,119361$.

18. Wu, C.; Zhu, Y.; Zhang, X.; Kou, S. Improving the properties of recycled concrete aggregate with bio-deposition approach. Cem. Concr. Compos. 2018, 94, 248-254. [CrossRef]

19. Kou, S.; Poon, C. Properties of concrete prepared with PVA-impregnated recycled concrete aggregates. Cem. Concr. Compos. 2010, 32, 649-654. [CrossRef]

20. Speath, V.; Tegguer, A. Improvement of recycled concrete aggregate properties by polymer treatment. Int. J. Sustain. Built Environ. 2013, 2, 143-152. [CrossRef]

21. Kong, D.; Lei, T.; Zheng, J.; Ma, C. Effect and mechanism of surface coating pozzolanics materials around aggregate on properties and ITZ microstructure of recycled aggregate concrete. Constr. Build. Mater. 2010, 24, 701-708. [CrossRef]

22. ACI Manual of Concrete Practice 209R-92. In Prediction of Creep, Shrinkage, and Temperature Effects in Concrete Structures; American Concrete Institute: Farmington Hills, MI, USA, 1997; pp. 1-47.

23. Siddika, A.; Mamun, M.; Ferdous, W.; Saha, A.; Alyousef, R. 3D Printed Concrete: Applications, Performance, and Challenges. J. Sustain. Cem. Based Mater. 2019, 9, 127-164. [CrossRef]

24. CEB 1990, "Evaluation of the Time Dependent Properties of Concrete", Bulletin d'Information No.199; Comite European du Beton/Federation Internationale de la Precontrainte: Lausanne, Switzerland, 1991; p. 201.

25. Wang, J.; Vandevyvere, B.; Vanhessche, S.; Schoon, J. Microbial carbonate precipitation for the improvement of quality of recycled aggregates. J. Clean. Prod. 2017, 156, 355-366. [CrossRef]

26. Mohr, P.; Hansen, W.; Jensen, E.; Pane, I. Transport properties of concrete pavements with excellent long-term in-service performance. Cem. Concr. Res. 2000, 30, 1903-1910. [CrossRef]

27. Li, S.; Roy, D.M. Investigation of relations between porosity, pore structure, and $\mathrm{Cl}$ diffusion of fly ash and blend cement pastes. Cem. Concr. Res. 1986, 16, 749-759. [CrossRef]

28. Wee, T.; Suryavanshi, A.; Tin, S.S. Evaluation of rapid chloride permeability test (RCPT) results for concrete containing mineral admixtures. ACI Mater. J. 2000, 97, 221-232.

29. Moffatt, E.; Thomas, M.; Fahim, A. Performance of high-volume fly ash concrete in marine environment. Cem. Concr. Res. 2017, 102, 127-135. [CrossRef]

30. Wee, T.; Suryavanshi, A.; Tin, S. Influence of aggregate fraction in the mix on the reliability of the rapid chloride permeability test. Cem. Concr. Compos. 1999, 21, 59-72. [CrossRef]

31. Asbridge, A.; Chadbourn, G.; Page, C. Effects of metakaoine and the interfacial transition zone on the diffusion of chloride ions through cement mortars. Cem. Concr. Res. 2001, 31, 1567-1572. [CrossRef]

32. Grattan-Bellew, P. Alkali contribution from limestone aggregate to pore solution of old concrete. ACI Mater. 1994, 91, 173-177.

33. Xie, P.; Beaudoin, J.; Brousseau, R. Effect of aggregate size on transition properties at the portland cement paste interface. Cem. Concr. Res. 1991, 21, 999-1005.

34. Aldea, C.; Young, F.; Wang, K.; Shah, S. Effect of curing conditions on properties of concrete using slag replacement. Cem. Concr. Res. 2000, 30, 465-472. [CrossRef]

35. Sasanipour, H.; Aslani, F. Effect of specimen shape, silica fume, and curing age on durability properties of self-compacting concrete incorporating coarse recycled concrete aggregate. Constr. Build. Mater. 2019, 228, 117054. [CrossRef] 
36. Khodair, Y.; Bommareddy, B. Self-consolidating concrete using recycled concrete aggregate and high volume of fly ash and slag. Constr. Build. Mater. 2017, 15, 307-316. [CrossRef]

37. Faella, C.; Lima, C.; Martinelli, E.; Pepe, M.; Realfonzo, R. Mechanical and durability performance of sustainable structural concretes: An experimental study. Cem. Concr. Res. 2016, 71, 85-96. [CrossRef]

38. Moore, W. Physical Chemistry, 4th ed.; Prentice-Hall: Englewood Cliffs, NJ, USA, 1972.

39. Julio-Betancourt, G.; Hooton, R. Study on the Joule effect on rapid chloride permeability values and evaluation of related electrical properties of concretes. Cem. Concr. Res. 2004, 34, 1007-1015. [CrossRef]

40. Yang, C.; Cho, S.; Huang, R. The relationship between charge passed and the chloride-ion concentration in concrete using steady-state chloride migration test. Cem. Concr. Res. 2001, 32, 217-222. [CrossRef]

41. Rajhans, P.; Gupta, P.; Kumar, R.; Panda, S.; Nayak, S. EMV mix design method for preparing sustainable self compacting recycled aggregate concrete subjected to chloride environment. Constr. Build. Mater. 2019, 199, 705-716. [CrossRef]

42. Rajhans, P.; Chand, G.; Kisku, N.; Panda, S.; Nayak, S. Propose mix design method for producing sustainable self compacting heat cured recycled aggregate concrete and its microstructural investigation. Constr. Build. Mater. 2019, 218, 568-581. [CrossRef]

43. Yang, S.; Lee, H.; Oh, I.; Lee, H.; Hwang, I. Properties of RCA Concretes Mixed with Cement Paste Dissociation Agent. In Proceedings of the 3rd International Conference on Bio-Based Building Materials, Belfast, UK, 26-28 June 2019.

44. KCS 1140 05: Reinforced Concrete Culverts; Korean Construction Specification; KICT: Goyang, Gyeonggi-do, Korea, 2016.

45. Juan, M.; Gutierrez, P. Study on the influence of attached mortar content on the properties of recycled concrete aggregate. Constr. Build. Mater. 2009, 23, 872-877. [CrossRef]

46. Rusinoff, A. Composition for protecting a body of concrete, a process for preparing same and a method for the protection of a body of concretes. U.S. Patent 5,728,428, 17 March 1998.

47. ASTM C192: Standard Practice for Making and Curing Concrete Test Specimens in the Laboratory; American Society for Testing Materials: West Conshohocken, PA, USA, 2012.

48. KS F 2424: Standard Test Method for Length Change of Mortar and Concrete; KATS: Seoul, Korea, 2015.

49. ASTM C157: Standard Test Method for Length Change of Hardened Hydraulic-Cement Mortar and Concrete; ASTM International: West Conshohocken, PA, USA, 2012.

50. ASTM C1202: Standard Test Method for Electrical Indication of Concrete's Ability to Resist Chloride ion Penetration; American Society for Testing Materials: West Conshohocken, PA, USA, 2019. 